\title{
Concepções de leitura e escrita em crianças do pré-escolar
}

\author{
Reading and writing conceptions in children of preschool education
}

Concepciones de lectura y escritura en niños/as de la educación infantil

\author{
ANA MARTA CARDOSO* \\ ÂNGELA BALÇA**
}

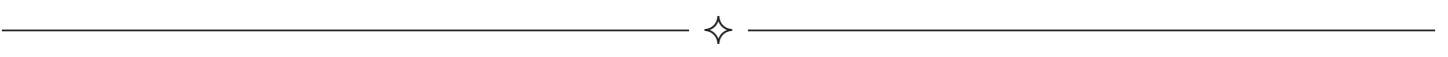

\begin{abstract}
RESUMO
Neste estudo, centrámo-nos nas concepções das crianças, sobre a leitura e a escrita, em idade pré-escolar. Os objectivos deste estudo foram investigar as concepções que as crianças tinham sobre a funcionalidade e utilidade da leitura e da escrita e identificar que conhecimentos revelavam as crianças sobre diferentes suportes de leitura e escrita. Utilizámos o paradigma metodológico da investigação-acção e a recolha de dados foi feita numa sala de educação pré-escolar, junto de crianças com 5/6 anos. Para esta recolha de dados utilizámos como instrumentos a entrevista semiestruturada e um conjunto de suportes de leitura e escrita de uso corrente. As conclusões apontaram para a par dos conhecimentos sobre a funcionalidade da leitura, todas as crianças evidenciaram possuir conhecimentos sobre diferentes suportes de leitura e escrita; e para a influência das práticas/contacto com a leitura e a escrita e materiais impressos no nível de elaboração das concepções das crianças, no que diz respeito à leitura e à escrita.
\end{abstract}

Palavras-chave: Leitura. Escrita. Educação pré-escolar.

\begin{abstract}
In this study, we focused in the conceptions of children on reading and writing in preschool. The objectives of this study were to investigate the conceptions that children had about the functionality and the utility of reading and writing and identify what knowledge revealed children about different supports reading and writing. We used the methodological paradigm of research-action and data collection was made in a pre-school class, with children 5/6 years old. For this we used data collection instruments such as semi-structured interview and a set of commonly used writing supports. The conclusions pointed to a pair of knowledge about the reading functionality, all children have demonstrated knowledge of different writing supports; and the influence of the practices / contact reading and writing and printing materials in the preparation of the level conceptions of children with regard to reading and writing.
\end{abstract}

Keywords: Reading. Writing. Pre-school education.

\section{RESUMEN}

En este estudio, nos centraremos en las concepciones de niños/as sobre la lectura y escritura en edad de preescolar. Los objetivos de este estudio fueron investigar las concepciones que los niños y niñas tienen sobre la funcionalidad e utilidad de la lectura y la escritura e identificar qué conocimientos rebelaban niños y niñas sobre diferentes soportes de lectura y escritura. Utilizamos el paradigma metodológico de la investigación-acción y la recogida de datos fue hecha en una aula de educación preescolar, con niños y niñas de 5/6 años. Para esta recogida de datos utilizamos como instrumentos la entrevista semi-estructurada y un conjunto de suportes de escritura de uso corriente. Las conclusiones apuntaron hacia los conocimientos sobre la funcionalidad de la lectura, todos los niños y niñas evidenciaron poseer conocimientos sobre diferentes soportes de escritura; y hacia la influencia de las prácticas/contacto con la lectura y la escritura y materiales impresos al nivel de elaboración de las concepciones de los niños/as, respecto a la lectura y escritura.

Palabras clave: Lectura. Escritura. Educación infantil.

\footnotetext{
*Licenciatura em Educação Básica pela Universidade de Évora, Portugal; Mestrado em Educação Pré-Escolar e Ensino do 1 Ciclo do Ensino Básico pela Universidade de Évora, Portugal. E-mail: < anamarta.cardoso2@gmail.com>.

**Doutoramento em Ciências da Educação pela Universidade de Évora, Portugal; Docente na Universidade de Évora, Portugal; Membro do CIEC - Centro de Investigação em Estudos da Criança, Universidade do Minho, Portugal. E-mail: <apb@uevora.pt>.
} 


\section{INTRODUÇÃO}

O presente estudo é fruto de uma investigação-acção ${ }^{1}$ que decorreu numa instituição de educação pré-escolar portuguesa. $\mathrm{O}$ tema que presidiu à nossa investigação centrou-se em redor das concepções das crianças, sobre a leitura e a escrita, em idade pré-escolar. Pensamos que, cada vez mais, a educação pré-escolar é basilar e determinante nos processos de ensino-aprendizagem que se seguem, sobretudo nas questões da leitura e da escrita. A maioria das crianças, quando entra para a escola, já possui representações sobre o acto de ler, o que pressupõe que a criança já teve oportunidade de pensar sobre a linguagem oral, a linguagem escrita e a relação entre ambas. Esta, certamente, já se coloca perante problemas a serem resolvidos a partir das suas construções e dos significados que elabora a partir do seu quotidiano. As oportunidades são dadas ao longo da educação pré-escolar, na qual a criança tem acesso a conhecimentos e conceitos relativos à linguagem escrita e à linguagem oral.

Muitos problemas noutras disciplinas escolares advêm de dificuldades relacionados com língua materna, pois esta constitui-se como um veículo de aprendizagem. Azevedo (2006) deixa clara a importância da língua materna assumindo que esta é um instrumento comunicativo, é uma ferramenta de descoberta determinante na potencialização de uma adequada actuação social, permitindo, também, partilhar, investigar, descobrir e criar. É assim essencial entender a língua como suporte e instrumento fundamental para o desenvolvimento social e cultural.

A escolha deste tema para investigação prendeu-se ainda com a importância que a escola ganha perante o ambiente familiar que cerca a criança e que, certamente, será mais restrito do que a escola, sendo colocado constantemente o desafio ao educador de infância e ao professor de levar as crianças mais além, dando-lhes oportunidades de contactar com formas mais complexas e mais elaboradas da língua, dotando-os de um "saber-fazer que lhes possibilite utilizarem proficuamente a língua em quaisquer contextos" (AZEVEDO, 2006, p. 3).

Este artigo divide-se, então, em quatro partes: a primeira diz respeito ao quadro teórico de referência que incide nas concepções da leitura e da escrita. De seguida, remetemos para a metodologia seguida na investigação e, numa terceira parte, interpretamos os resultados obtidos à luz das práticas que os influenciaram. Por fim, o último ponto remete para as conclusões.

\section{CONCEPÇÕES DE LEITURA E ESCRITA EM CRIANÇAS DA EDUCAÇÃO PRÉ-ESCOLAR}

A importância da linguagem não carece de qualquer tipo de justificação, pois está de tal modo enraizada na experiência do homem que é impossível imaginar a vida humana sem ela. A aquisição da linguagem é natural, intuitiva, subconsciente e espontânea e não difere entre raças, culturas ou grupos sociais, pois a linguagem é uma capacidade da espécie humana. Para que haja aquisição, a criança tem de estar imersa em meios que despertem o desenvolvimento da linguagem e por isso o contexto social e as relações adulto-criança são fundamentais ao longo de todo o processo.

Um dos grandes desafios colocados aos educadores de infância é serem mediadores deste processo; o outro é as possibilidades que têm de facilitar o contacto com a escrita e com a leitura desde tenra idade. A educação pré-escolar é o início de um longo caminho educativo que tem grande influência no sucesso escolar e social da criança. Por isso, o educador de infância tem de olhar para o espaço do jardim-de-infância como um espaço de aprendizagens estruturantes e decisivas.

Até à entrada no ensino formal, a criança adquiriu e aprendeu informalmente inúmeros conceitos que podem servir como ponto de partida para determinadas actividades. Embora possa não conhecer os símbolos alfabéticos, a criança já consegue estabelecer ligações entre o significado e o significante, relacionar sons, estabelecer relações, ordenar, classificar, organizar.

Não menos importante é o desafio do professor, que se coloca noutra perspetiva que é a da aprendizagem formal da leitura e da escrita, sem esquecer o processo antecedente de aquisição, de aprendizagem, de desenvolvimento e de contacto precoce.

Com a entrada para a escola, a criança confronta-se com uma nova modalidade da linguagem. A aprendizagem da vertente escrita da língua representa um progresso para o seu desenvolvimento linguístico, pois permite uma reflexão mais elaborada sobre um conhecimento já adquirido bem como novas formas de aceder à informação, que antes não estavam disponíveis. A linguagem, que anteriormente era usada como um instrumento para a comunicação, cujos processos eram essencialmente de natureza implícita, passa agora a ser objecto de uma reflexão consciente, ou seja, os processos tornam-se de natureza explícita, com caráter reflexivo e sistematizado que tende ao exercício do controlo normativo da produção verbal oral e escrita.

A capacidade de manipular elementos impressos, desde os mais simples aos mais complexos, constitui uma competência denominada literacia ${ }^{2}$ (TEALE; SULZBY, 1995). Antes de entrar para a escola, a criança tem oportunidade de explorar os mais diversos suportes de leitura e escrita, o que lhe consentirá o desenvolvimento de conhecimentos, que serão os alicerces para a aprendizagem do código escrito. Estas aquisições

\footnotetext{
${ }^{1}$ Em Português do Brasil, pesquisa-acção.
}

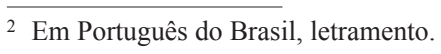


literácitas ${ }^{3}$ vão determinar, ao longo do percurso escolar, a qualidade de muitas aprendizagens.

A literacia emergente, segundo Whitehurst e Lonigan (2003), aponta para os conhecimentos, as capacidades e as atitudes que se constituem como precursores do desenvolvimento da linguagem escrita e que têm lugar antes do seu ensino formal, que corresponde à entrada no $1^{\underline{O}}$ ano de escolaridade. ${ }^{4}$ Por conseguinte, a literacia emergente assume-se como a primeira fase da construção e do desenvolvimento da literacia, permitindo, por um lado, a compreensão de muitas características e funções das linguagens falada e escrita e, por outro lado, a formação de conceitos e o desenvolvimento de capacidades específicas de leitura e de escrita (SMITH; DICKINSON, 2001).

De facto, a literacia emergente pressupõe um conjunto de experiências sociais interativas, com sentido, as quais, na educação pré-escolar, onde não há ensino da língua, permitem à criança adquirir a consciência do impresso, adotar comportamentos de leitor/escritor, formular hipóteses sobre a linguagem escrita e a relação que a mesma estabelece com a linguagem falada e até perceber que se trata de um meio de comunicação útil, que integra, de forma natural, o dia-a-dia.

Deste modo, a literacia emergente permite estabelecer um continuum entre a pré-leitura/escrita e a leitura/escrita propriamente dita, fundando a construção e favorecendo o desenvolvimento de competências e atitudes que vão ser essenciais nos primeiros anos de escolaridade. Estamos, assim, perante algo de extrema importância e que vai mais além da leitura e da escrita propriamente ditas. Poder-se-á afirmar que está também presente um processo de aquisição de competências de fala em idade pré-escolar, que se caracteriza por ser activo, mobilizador, bastante interactivo e experiencial.

Ressalta daqui a ligação entre fala e escrita, já que, nesta fase, a aprendizagem da leitura e da escrita se encontra embebida no sistema de comunicação oral. De facto, a literacia emergente remete-nos para a aquisição e o desenvolvimento de um conjunto de relações entre leitura e escrita, relações estas que têm por base a fala e a audição, pois, como nos dizem Roskos, Christie e Richgels (2003),

young children need writing to help them learn about reading, they need reading to help them learn about writing; and they need oral language to help them learn about both (ROSKOS; CHRISTIE; RICHGELS, 2003, p. 3).

\footnotetext{
3 Em Português do Brasil, aquisições relacionadas com o letramento.

4 No sistema educativo português, o 10 ano de escolaridade corresponde ao início da escolaridade obrigatória, tendo as crianças cerca de 6 anos. Corresponde ao $1^{\mathrm{O}}$ ano do ensino fundamental no sistema educativo brasileiro.
}

Importa referir, ainda, quais os percursores básicos e desenvolvimentais em termos de literacia e capacidades: a consciência fonológica e a consciência do impresso, nomeadamente a capacidade de reconhecer material escrito, o conhecimento da relação entre a fala e a escrita e o conhecimento dos mecanismos da escrita, e o conhecimento do código que, neste caso, nos remete para o conhecimento das letras do alfabeto e por conseguinte das relações entre essas letras e os sons.

A estes precursores básicos juntam-se outros dois: a leitura, onde a criança ouve, individualmente e em pequeno grupo, ler de forma interactiva; e a escrita, nomeadamente, as pré-escritas e a capacidade de escrever o nome, sobre o qual recai bastante importância pelas potencialidades que tem em sala de jardim de infância. Saliente-se que, sobre este último domínio, o desenho, marca própria da educação pré-escolar, desempenha um papel importante, pois frequentemente a escrita emerge do desenho e é, muitas vezes, inspirada por ele. De acordo com Ferreiro e Teberosky (1999), a criança, no nível pré-silábico, utiliza um conjunto de desenhos, letras e outros sinais gráficos que se destacam da representação dos objectos propriamente ditos e que dependem da idade e/ou do nível de desenvolvimento da criança. Assim, as crianças mais velhas, de 4 e 5 anos, são já capazes de incluir nos seus desenhos letras e até palavras, com especial destaque para o seu nome.

Por fim, como percursores básicos temos ainda os jogos de literacia que, de forma lúdica, permitem à criança um conjunto de experiências e de interacções com os instrumentos de literacia e com a leitura e a escrita propriamente ditas. Saliente-se que, apesar de não ser específico da linguagem escrita, o jogo é considerado um caminho para atingir esse fim, pois, parafraseando Roskos, Christie e Richgels (2003), a ligação da literacia ao jogo é uma das formas mais eficazes de fazer com que as diversas actividades façam sentido para a criança e, ao mesmo tempo, sejam agradáveis de realizar.

Para que as crianças possam aprender a ler, necessitam de ter presente os objectivos, a função e a natureza da leitura. De facto, as crianças têm de começar por descobrir a funcionalidade da leitura, ou seja, perceber que esta é uma forma de comunicação, tomar consciência da variabilidade de objectivos da leitura e da sua relação com diferentes formas de ler e, por fim, construir um Projecto Pessoal de Leitor.

Para que haja esta construção de um Projecto Pessoal de Leitor, as crianças têm de ouvir ler coisas que lhes interessem e com as quais sintam prazer, a fim de desejar serem elas próprias leitoras. Então, os factores volitivos surgem aqui como factores determinantes que ditam as motivações das crianças para aprenderem. Um Projecto Pessoal de Leitor 
caracteriza-se pelo modo como as crianças dão sentido à aprendizagem da leitura e da escrita, sendo visível pelo facto de conseguirem atribuir várias razões funcionais para essa aprendizagem (por exemplo, para ler histórias, cartas, as legendas dos filmes, revistas, etc.) (MATA, 2008 p. 16).

Ainda de acordo com Mata (2008),

o projecto pessoal de leitor prende-se diretamente com o querer aprender a ler e a escrever, pois isso vai permitir utilizar esse saber de modo funcional, dando resposta à resolução ou desenvolvimento de situações concretas. Pode, então, considerar-se que ele resulta de uma interiorização pela criança das finalidades da escrita, conseguindo, desse modo, dar sentido ao processo de aprendizagem, pois tem razões pessoais que justificam o seu envolvimento nessa aprendizagem (MATA, 2008, p. 16-17).

A apropriação da funcionalidade e da utilidade da linguagem escrita, por parte das crianças vai, certamente, concorrer para que elas compreendam a importância conferida à leitura e à escrita. Cremos que aprender os usos da leitura e da escrita, atribuindo-lhes funções, conduz a um verdadeiro envolvimento da criança, desenvolvendo a compreensão e a apropriação gradual das finalidades da escrita bem como as características e as convenções da mesma.

No que se refere à natureza do código escrito, as crianças têm de começar por perceber quais são as propriedades da linguagem oral representadas na escrita e quais as regras que orientam a passagem da linguagem oral aos signos convencionados para a escrita. Para isso, as crianças têm de ser capazes de pensar sobre a linguagem e isso não significa que, pelo simples facto de produzir e perceber o discurso oral, se esteja a pensar sobre a linguagem, pois o uso é diferente da consciência reflexiva sobre esta.

Ferreiro (2007) afirma que precisamos de superar uma visão que considera unicamente os pré-requisitos para a aprendizagem como uma série de destrezas que permitam que a criança se aproprie da linguagem escrita. Ainda segundo Ferreiro (2007), precisamos pensar em antecessores cognitivos, que são as ideias e concepções que a criança constrói antes de chegar a escola.

Vários são os estudos que abordam a temática e uma das linhas de investigação é a de Ferreiro e Teberosky (1999) que se detém sobre a forma como as crianças pensam a aprendizagem da leitura, ou seja, as suas concepções sobre a leitura antes do ensino formal. Estas investigadoras analisaram o modo como as crianças dominam as convenções da linguagem oral e da linguagem escrita. Alguns dos seus trabalhos mostram igualmente a importância dos conhecimentos precoces sobre a linguagem escrita na aprendizagem da leitura. Para além das capacidades metalinguísticas, os conhecimentos que as crianças têm sobre as utilizações funcionais da leitura e a apropriação que delas fazem desempenham um papel importante na aprendizagem da leitura. O nível dessas concepções, a sua maior ou menor proximidade das de uma criança escolarizada, depende do maior ou menor contacto e das interacções que as crianças tiveram possibilidade de realizar com o texto escrito.

Uma das formas de tentar caracterizar e compreender os conhecimentos e concepções das crianças é através das suas produções escritas, que na educação pré-escolar resultam quer de muitas experiências individuais ou colectivas quer de pedidos explícitos feitos pelo adulto para a reflexão sobre a língua. Segundo Mata (2008), as produções escritas podem ser analisadas em dois aspectos distintos: os aspectos figurativos, passíveis de serem observados, dão informações ao adulto sobre o tipo de características preceptivas ou gráficas que as crianças já se aperceberam relativamente à escrita, por exemplo a diferenciação de códigos (desenho e escrita), a orientação da escrita ou o conhecimento de letras; e os aspectos conceptuais, através dos quais o educador de infância compreende a forma como as crianças interpretam e integram todos os conhecimentos e características que atribuem à escrita e que se tornam identificáveis quando o educador fala com as crianças, questionando-as, tentando compreender as razões que as levaram a determinadas opções de escrita e a forma como estas concebem o funcionamento da escrita.

Para que haja um progresso em termos conceptuais é necessário a apreensão de princípios que apoiem as crianças e que só é conseguido pelo envolvimento em actividades reais de escrita devidamente significativas e contextualizadas na sua vida e no seu ambiente.

A consciência fonológica é outro factor determinante na evolução e no estabelecimento de ligações entre a escrita e a oralidade. A consciência fonológica prende-se com a compreensão de que as palavras são formadas por sons e é uma competência de reflexão sobre a linguagem oral, mas torna-se essencial na evolução das concepções que as crianças têm sobre a escrita, pois só com a sua aquisição gradual se consegue estabelecer relações mais sistemáticas entre o oral e o escrito até chegar à escrita alfabética.

A forma como as crianças evoluem e progridem nas suas conceptualizações depende das oportunidades que tiveram de interagir com o escrito, de experimentar, de reflectir, dos apoios que tiveram e das respostas que foram obtendo às questões que foram colocando. Importa deixar claro que o respeito pelas características conceptuais de cada um, o não acelerar nem retardar ou saltar etapas, respeitar o tempo e as oportunidades que cada criança precisa assim como as suas competências individuais permite que haja uma evolução saudável e ajustada a cada criança. 


\section{Metodologia}

Neste estudo, seguimos como metodologia a investigação-acção, uma vez que este paradigma metodológico permite que nos debrucemos sobre a relação entre o desenvolvimento do profissional e o contexto, como sendo um processo vivencial. Este paradigma metodológico possibilita ainda o atenuar da dualidade entre teoria e prática, sendo possível agir reflectidamente.

Tendo por base os estudos apresentados, e sabendo a riqueza do contexto educativo onde realizámos esta investigação, pretendemos com este estudo compreender que conhecimentos possuem as crianças sobre a funcionalidade, natureza e utilidade da leitura e da escrita. Assim, constituem-se como objectivos deste estudo investigar as concepções que as crianças têm sobre a funcionalidade e utilidade da leitura e da escrita; e identificar que conhecimentos revelam as crianças sobre os diferentes suportes de leitura e escrita.

Numa sala de educação pré-escolar, num grupo de 25 crianças, elegemos a amostra para esta investigação tendo em conta as crianças que iriam transitar para o $1^{\circ}$ ano de escolaridade, o que se traduz em 14 sujeitos; três deles frequentavam a educação pré-escolar pela primeira vez. A idade média das crianças da amostra era compreendida entre os 5 e os 6 anos de idade.

Vários foram os instrumentos de recolha de dados. Um destes instrumentos de recolha de dados, utilizado para aprofundamento das questões sobre as concepções das crianças, no que diz respeito à leitura e à escrita, foi a realização de entrevistas. Tendo em conta o contexto em que iriam ser realizadas as entrevistas, optámos por estas terem um carácter semiestruturado e, posteriormente, elas foram alvo de uma análise de conteúdo.

O guião ${ }^{5}$ da entrevista semiestruturada a cada criança serviu para avaliar a apropriação das utilizações funcionais da leitura e da escrita. As entrevistas baseavamse num conjunto de questões que tinham como objectivo a caracterização do conhecimento que as crianças possuíam sobre a funcionalidade atribuída à leitura e à escrita. Pretendíamos, ao longo das entrevistas, levar as crianças a verbalizarem e a concretizarem situações funcionais de utilização da leitura e da escrita de que já se tivessem apercebido, através de contactos mais ou menos formais com o código escrito.

Sentimos ainda como necessário identificar que conhecimentos revelavam as crianças sobre os diferentes suportes de leitura e de escrita com os quais se poderiam deparar no dia-a-dia. Deste modo, como instrumento de recolha de dados, reunimos um conjunto de suportes de leitura e escrita de uso corrente e pedimos a cada criança, da amostra já definida, que os identificasse e

\footnotetext{
5 Em Português do Brasil, roteiro.
}

dissesse o que estaria lá escrito. Assim elaborámos um guião com duas colunas - o que é isto e o que está aqui escrito - para nos orientarmos e dialogarmos com as crianças de forma calma. O material escolhido é todo ele sobrevestido de caráter utilitário, daí pretendermos verificar se as crianças reconheciam a sua utilidade e funcionalidade. Nas respostas obtidas foi tido em conta se as crianças identificaram o suporte de leitura e escrita pela leitura de imagens (identificação pela apresentação do material, capa) ou pela leitura do texto (identificação do material e sua função). Assim foram apresentados a cada criança, de forma individual, vários suportes de leitura e escrita, nomeadamente: um manual escolar, ${ }^{6}$ um livro de histórias, um envelope selado com nome e morada escritos, um convite de aniversário, um jornal, uma revista, um livro de receitas, uma factura ${ }^{7}$ da água e um folheto de supermercado com imagens e preços. Os dados recolhidos, com estes instrumentos de recolha de dados, foram objecto de uma análise quantitativa.

\section{O ESTUDO: DESCRIÇÃO, ANÁLISE E DISCUSSÃO DOS RESULTADOS}

Neste ponto do artigo apresentamos o estudo, com a descrição, a análise e a discussão dos resultados da nossa investigação-acção em contexto de educação pré-escolar. Em primeiro lugar daremos relevo aos resultados das entrevistas semiestruturadas; em segundo lugar, exporemos os resultados obtidos, da apresentação às crianças, dos suportes de leitura e escrita que remetem para os materiais impressos.

O guião da entrevista semiestruturada era constituído pelas seguintes questões: Para que é que queres aprender a ler?; Para que serve saber ler?; O que é que poderás fazer quando souberes ler?; Quando já souberes ler, o que gostarias de ler?. As respostas foram categorizadas e as categorias foram criadas com base na definição do discurso de cada criança, através de termos chave que remetem para a funcionalidade da escrita concebida por cada uma das crianças da amostra. A análise de conteúdo efectuada, para cada questão, permitiu conhecer as diferentes utilizações funcionais da leitura por elas referidas. Foram consideradas respostas funcionais as que remetiam para funções de ficção, informativas, utilitárias, comunicativas ou ligadas à formação de saberes ou conhecimentos. Procurámos que todas as crianças dessem uma resposta possível de ser analisada e o seu conteúdo fosse passível de ser categorizado, para melhor interpretarmos essas respostas. Tendo em conta o discurso das crianças, tentámos recolher a informação

\footnotetext{
${ }^{6}$ Em Português do Brasil, livro didáctico.

7 Em Português do Brasil, conta da água.
} 
respeitando o mais possível as expressões utilizadas e o seu significado (BARDIN, 2004).

Quanto à primeira questão, Para que é que queres aprender a ler?, conforme as respostas, elegemos quatro grandes categorias: ler, escrever, saber e contar. Pudemos constatar que as crianças que responderam a esta questão referiram que querem aprender a ler para ler livros. Ainda nesta categoria as crianças referiram também que desejam aprender a ler para efectuar a leitura de cartazes ou rótulos. Pensamos que estas respostas surgem pela importância que foi dada à leitura na sala, isto é, os momentos de leitura em grande grupo eram sempre ocasiões de grande interacção, de curiosidade e de oportunidade de contacto com o livro. Estas crianças frequentavam também, com muita regularidade, a biblioteca e a influência da família foi notória, sendo referidos os seus comportamentos leitores (Para ler livros como a minha mãe e o meu pai fazem).

Além da leitura, as crianças querem aprender a ler para também aprenderem a escrever. A totalidade das respostas nesta categoria mencionava o computador como instrumento de escrita (Para poder escrever no meu computador). Nesta sala, havia a rotina de realizar registos das actividades e, para isso, a maioria das vezes, as crianças eram convidadas ou ofereciam-se para a tarefa de copiar de uma folha com letra de imprensa e escrever no computador, num processador de texto adequado. Esta era também uma das áreas da sala mais aliciante e apetecível.

As categorias saber e contar, apenas um grupo restrito de crianças as mencionou. Todas as crianças que as mencionaram tinham irmãos mais velhos, daí, parece-nos, poderem atribuir este valor e funcionalidade à aprendizagem da leitura.

As respostas dadas por estas crianças revelam-nos que o trabalho em sala e as práticas de literacia familiar potenciam a construção, por partes destas crianças, daquilo que Mata (2008) denominou como Projecto Pessoal de Leitor. Estas crianças, tal como Mata (2008) referiu, dão sentido à aprendizagem da leitura e da escrita e são capazes de conferir razões funcionais a essas aprendizagens.

Por outro lado, constatamos que algumas destas crianças já conseguem estabelecer relações entre a leitura e a escrita pois, como afirmam Roskos, Christie e Richgels (2003), a leitura auxilia as crianças a aprenderem sobre a escrita e a escrita ajuda-as a aprenderem sobre a leitura.

$\mathrm{Na}$ questão seguinte desta entrevista, Para que serve saber ler?, voltámos a obter quatro categorias de resposta: ler, aprender, saber, contar, porém as respostas foram menos variadas. As crianças entrevistadas consideraram que saber ler serve literalmente para ler, mencionando leituras do seu interesse como, na maioria, histórias e outros livros (Tenho lá livros que só vejo os desenhos e depois já se podem ler) e mais uma vez mencionaram o computador como instrumento para aplicar o acto de leitura.

Nesta questão, $\mathrm{O}$ que tu poderás fazer quando souberes ler?, a variedade e a distribuição das respostas pelas diferentes categorias aumentou substancialmente. As categorias obtidas foram ler, escrever, jogar, comprar, ensinar. As respostas a esta questão eram de caráter mais pessoal. Tal como nas questões anteriores, as crianças atribuíram utilidade à leitura na vertente da leitura em si e da escrita. Em ambas as categorias (ler e escrever), as crianças referiram tarefas da sala que eram concretizadas todos os dias mais do que uma vez, por exemplo poder ler as letras das canções novas que se cantavam na sala (Posso ler as letras das canções novas que cantamos na sala) ou poder escrever o nome de qualquer criança sem o cartão-modelo (Posso escrever o nome de qualquer menino sem cartão). Todavia, as crianças atribuíram mais três funções concretas ao que poderão fazer quando souberem ler: jogar (Posso jogar os jogos que o meu primo joga); comprar (Posso saber o que comprar para comer); e ensinar (Quero ensinar a minha avó a ler).

As respostas das crianças a estas duas questões revelam-nos que as mesmas se vão apropriando da funcionalidade da linguagem escrita, aspecto fulcral para a aprendizagem da leitura e da escrita, de acordo com Ferreiro e Teberosky (1999), com Mata (2008) ou com Smith e Dickinson (2001).

Por fim, apresentámos a questão $\mathrm{O}$ que gostarias de ler?, para a qual, através das respostas dadas pelas crianças, obtivemos nove categorias distintas: histórias, letras, legendas, mensagens, cartazes, nomes, jornal, receitas e papéis. Verificámos que a categoria livros/ histórias foi das mais mencionadas pelas crianças, talvez pela prática que havia em torno da leitura de histórias no dia-a-dia das mesmas. Em várias categorias, como por exemplo: receitas (Gostava de ler onde diz como a minha mãe tem de fazer o bolo e o que põe na taça para fazer o bolo) e nomes (Gostava de ler o nome dos meus pais), através das respostas obtidas notava-se a vinculação ao ambiente familiar e como este influenciava a criança nas suas motivações para aprender a ler e a escrever. Apenas uma criança mencionou que queria ler os papéis das pessoas, associando o papel à escrita e por sua vez à leitura dessa mensagem. As restantes categorias surgiram com muito pouca frequência, apenas uma ou duas crianças, e pareceram indicar a necessidade de satisfação de alguns aspectos recentes na vida da criança.

$\mathrm{Na}$ verdade, estas crianças mostraram já ter alguma capacidade de dizer o que gostariam de ler, apresentando uma interiorização das finalidades da escrita, fundamentais, mais uma vez de acordo com Mata (2008), para a construção do seu Projecto Pessoal de Leitor.

Passemos agora aos suportes de leitura e escrita, que remetem para os materiais impressos, apresentados às 
crianças. A apresentação às crianças destes suportes de leitura e escrita foi feita em conjunto com duas questões: O que é isto? e $\mathrm{O}$ que está aqui escrito? Recordamos que os suportes de leitura e escrita, apresentados às crianças, eram um manual de leitura, um livro de histórias, um envelope selado com nome e morada escritos, um convite de aniversário, um jornal, uma revista, um livro de receitas, uma factura da água e um folheto de supermercado com imagens e preços.

Para a questão O que é isto?, procedemos mais uma vez à categorização da informação e, para isso, agrupámos todos os termos utilizados pelas crianças na nomeação do suporte de leitura e escrita. Sendo assim, o critério seguido foi o tipo de identificação feito por elas.

Os suportes de leitura e escrita mais conhecidos pelas crianças eram o livro, quer o manual escolar (100\%) quer o livro de histórias $(100 \%)$, o jornal $(100 \%)$ e a revista $(100 \%)$. É importante salientar que o manual escolar foi referido várias vezes como o livro da escola para se aprender e, quanto ao livro de histórias, quando a questão foi colocada, a maioria referiu oralmente que, enquanto este livro tinha uma história do Capuchinho Vermelho, ${ }^{8}$ o outro apenas tinha letras. Queremos deixar claro que os livros de histórias faziam parte da biblioteca escolar e da biblioteca da sala bem como do dia-a-dia familiar destas crianças. O manual escolar era adoptado na escola, no $1^{\mathrm{O}}$ ano de escolaridade e, por isso, algumas crianças da amostra poderiam ter contactado com este através de irmãos mais velhos ou com exemplares que apresentassem alguma semelhança física.

Quanto ao jornal e à revista, ambos identificados rapidamente pelas crianças da amostra, importa referir que estes suportes de leitura e escrita estavam na sala e eram de uso regular em actividades nas diferentes áreas pedagógicas ou até mesmo para cuidado do espaço. Nesta sala, nos jornais e nas revistas, as crianças ouviam ler/ liam uma notícia, uma receita de culinária, mas também, quando já eram velhos, faziam recortes, dobragens ou forravam o chão para não o pintar.

O envelope selado e o livro de receitas foram dois suportes de escrita identificados por mais de metade das crianças ( $76 \%$ ambos). Apenas $24 \%$ da amostra não conseguiu dar a denominação convencionada mas, através das respostas das crianças, percebemos que não estiverem longe da função do material impresso que tinham na mão e puderam manusear.

O folheto do supermercado, apesar de ser uma presença constante nas caixas de correio ou até mesmo nos estabelecimentos comerciais, foi identificado por $50 \%$ das crianças como um jornal, pareceu-nos devido ao seu formato e ao modo como as crianças o manipulavam. Dada à sua semelhança com os jornais, concretamente no tamanho

\footnotetext{
${ }^{8}$ Em Português do Brasil, Chapeuzinho Vermelho.
}

e nas várias folhas soltas, afigurou-se-nos que as crianças terão confundido o folheto do supermercado com o jornal.

O convite de aniversário foi identificado pela maioria das crianças $(60 \%)$, contudo uma parte significativa, $10 \%$, intitulou-o carta, $16 \%$ não reconheceu o suporte de leitura e escrita e $14 \%$ descreveu a imagem.

Por fim, a factura da água foi identificada por $53 \%$ das crianças, que referiu estar perante algo a pagar, pela presença do símbolo do euro $(€)$ e pela existência de números. A outra metade dos inquiridos identificou-a como sendo uma carta pela forma como estava dobrada $(20 \%)$ e apenas identificaram o material - papel - $27 \%$ dos inquiridos. Algumas crianças, que identificaram o impresso como carta, frisaram: A mãe e o pai é que abrem cartas de adultos; ou A mãe é que sabe ler esses números com letras. Sendo assim, podemos depreender que estes entenderam que a função daquele suporte de leitura e escrita é para algo que é da obrigação de um adulto e que ainda não lhes cabe a eles. Por fim, não reconhecer este material também pode ter por base o desuso do envio de cartas, dada a substituição que é feita pelo envio destes documentos on-line.

De qualquer modo, o conhecimento que muitas destas crianças revelaram destes suportes de leitura e escrita remete-nos para as considerações de Teale e Sulzby (1995), que nos chamam a atenção para a capacidade da criança manipular elementos simples e complexos de elementos impressos, o que contribui sobremaneira para o desenvolvimento de aquisições literácitas por parte destas.

$\mathrm{Na}$ questão $\mathrm{O}$ que está aqui escrito, surgiram respostas que apontaram para quatro categorias. Assim, as respostas foram tidas em conta se o suporte de leitura e escrita foi identificado pela leitura de imagens (identificação pela apresentação do material ou seja quando os sujeitos nomeavam o material pelo seu aspecto exterior e imagens que apresentavam) ou pela leitura do texto escrito (identificação do material e sua função, ou seja, os sujeitos faziam associações entre o aspecto do material e o tipo de texto que apresentava, sugerindo a sua função). As outras duas categorias remetiam para leitura inventada pela criança (quando as respostas dadas não apresentavam qualquer relação com o aspecto exterior do material nem com o texto impresso nele presente) e para "não sei", por terem existido crianças que não conseguiram atribuir qualquer nome/função ao material.

Nas respostas pudemos verificar que, relativamente ao manual escolar, $55 \%$ das crianças inquiridas nomearam o material pela sua apresentação; $35 \%$ da amostra identificou o material e a sua função dizendo que servia para aprender, para escrever e que era material escolar. Apenas $10 \%$ não conseguiu atribuir função ao material apesar de ter reconhecido que era um livro.

Quanto ao livro de histórias apresentado, foi elevada a percentagem de crianças $(78 \%)$ que identificou o 
material pela sua apresentação, através das ilustrações, dando muitas vezes a justificação de que era um livro de histórias porque tinha capa e tinha imagens. As restantes crianças $(22 \%)$ identificavam o material e a função dizendo que ali estavam letras que serviam para lermos.

No que diz respeito ao envelope selado, as crianças maioritariamente $(80 \%)$ souberam atribuir a função correcta ao objecto que tinham na sua frente, dizendo explicitamente que era uma carta. Cerca de $4 \%$ das crianças disse que se tratava de coisas para comprar, o que não corresponde à verdadeira função do objecto. Ainda $16 \%$ das crianças inquiridas não souberam atribuir função e, dentro destas, estão incluídas $7 \%$ de crianças que identificou o material impresso como sendo somente papel.

Relativamente ao convite de aniversário, apenas 18\% identificou o material somente pela sua apresentação. Porém, $68 \%$ das crianças identificou a sua função, dizendo que o que estava escrito era o que diziam os convites das festas, afirmando-se esta como uma única hipótese para a categoria da leitura do texto escrito. Por fim, 13\% dos inquiridos não soube atribuir função ao material mesmo mexendo nele várias vezes.

Para o livro de receitas, pudemos constatar que $82 \%$ das crianças identificaram o material somente pela leitura das imagens, dizendo apenas que ali estava "bacalhau", "pão", "peixe". Os restantes $18 \%$ das crianças conseguiram identificar o material e a sua função, chegando um dos sujeitos a afirmar que isto aqui são os ingredientes (apontando para a lista de ingredientes) e aqui é como se faz (apontando para o texto da preparação).

Quanto ao jornal, $16 \%$ das crianças identificou-o pela página inicial; $84 \%$ das crianças conseguiu identificar o material pelo texto apresentado e pela sua função, referindo que se tratavam de notícias.

Em relação à revista, $100 \%$ das crianças respondeu de forma ajustada. Contudo, importa referir que embora os inquiridos tenham identificado o material e a função, a interpretação do texto escrito foi muito além das nossas expectativas. As crianças identificavam, enquanto folheavam a revista, que existiam "coisas para mulheres" ou "coisas de novelas" e atribuíam a função de que numa revista se pode ler e saber, e muitas crianças até diziam "como no jornal".

Quanto à factura da água, pudemos concluir que este foi o impresso em que mais crianças disseram claramente que não sabiam o que estava lá escrito. Porém, este foi o suporte de leitura e escrita que as crianças mais tempo tiveram para observar. Assim, 26\% das crianças identificaram letras e números, tendo sido interessante poder ver como elas, olhando para o papel, disseram que se tratava de uma conta para pagar; outras identificaram um símbolo e disseram que era do Município. A maioria dos que não identificaram a factura da água (25\%) remeteu para algo com importância dizendo: "tem coisas importantes"; "contas para pagar"; "coisas do hospital"; "da Câmara"; "do médico"; e um dos sujeitos disse "da Segurança Social".

Por fim, em relação ao folheto do supermercado, $30 \%$ das crianças deu resposta com base nas imagens contidas neste suporte de leitura e escrita. Os restantes remeteram as suas respostas para o carácter funcional do suporte de leitura e escrita, reconhecendo onde estava escrito o nome das frutas ou preços.

Os resultados obtidos com esta prova mostram que existe uma grande conciliação entre o que representa o texto e a consideração das propriedades do mesmo que rementem para a sua funcionalidade. As respostas dadas por estas crianças vão ao encontro dos estudos de Ferreiro e Teberosky (1999), uma vez que estas crianças revelam já conhecimentos sobre as utilizações funcionais da leitura e da escrita. A apropriação, por parte das crianças, destas utilizações funcionais da leitura e da escrita desempenham, de acordo com Ferreiro e Teberosky (1999), um papel importante na aprendizagem da leitura. Na verdade, são estes contactos e estas utilizações funcionais da leitura e da escrita que permitirão às crianças, no futuro, e segundo Azevedo (2006), utilizarem a sua língua materna proveitosamente em qualquer contexto.

\section{Conclusões}

Neste estudo, centrámo-nos em redor das concepções das crianças, sobre a leitura e a escrita, em idade préescolar, dado que esta etapa, no percurso de vida das mesmas, é fundamental nos processos de ensinoaprendizagem posteriores.

Os objectivos que presidiam a este estudo eram investigar as concepções que as crianças tinham sobre a funcionalidade e utilidade da leitura e da escrita; e identificar que conhecimentos revelavam as crianças sobre os diferentes suportes de leitura e escrita. A recolha de dados foi feita numa sala de educação pré-escolar, junto de crianças com 5/6 anos. Para esta recolha de dados utilizámos como instrumentos a entrevista semiestruturada $\mathrm{e}$ um conjunto de suportes de leitura e escrita de uso corrente.

Ao categorizar o conteúdo das respostas recolhidas, através das entrevistas semiestruturadas, os resultados mostraram que a maioria das crianças considerava o acto de ler o mais importante, atribuindo-lhe um elevado número de funções, como ler livros, histórias, cartazes de rua, rótulos, mensagens, informações no computador. Também à escrita atribuíam várias funções que não se restringiam à escola, como a escrita de cartas, de mensagens no computador e, para nós, o mais interessante, escrever sem ajuda. As crianças consideraram que a aprendizagem da leitura e da escrita também lhes possibilitava um certo grau de autonomia. Assim, pudemos concluir que as crianças possuíam representações funcionais da leitura elaboradas.

A maioria das crianças entendia que a aprendizagem da leitura possibilitava o conhecimento e o entendimento 
do mundo, na medida em que ler significa ter acesso a informações com as quais se deparavam e que eram possíveis de interpretar com a aprendizagem da leitura. Em geral, todas elas compreenderam as intenções e finalidades da leitura, referindo diversas vezes que uma das funções atribuídas à leitura era a de ser possível ler para outros ou mesmo ensinar. A percentagem de crianças que atribuiu funções à leitura, ligadas ao conhecimento, foi também significativa.

De facto, um grande número de crianças revelou o desejo de aprender, referindo-se à leitura como um meio essencial para saber mais. Algumas crianças mostraram até ser capazes de pensar na funcionalidade da leitura projectando-se no futuro (curso académico, profissão...). Foi interessante verificar que crianças que iam iniciar o ensino formal tinham, a maioria, a clara noção de que ler era uma tarefa extremamente importante, sendo imprescindível para aprender, estudar ou ter uma profissão. Se tivermos em conta que estamos inseridos numa sociedade, na qual a leitura e a escrita são ferramentas essenciais na vida das pessoas, nomeadamente na esfera profissional, estes resultados são bastante compreensíveis. Assim, as crianças desde pequenas estão inseridas num meio que valoriza a escrita, daí conferirem à mesma uma importância significativa não só no presente, mas também no futuro.

No que diz respeito aos conhecimentos que possuíam sobre os conteúdos dos suportes de leitura e escrita, pudemos verificar que as crianças revelaram mais conhecimentos sobre os materiais com que estabeleciam contactos mais frequentes no seu quotidiano, como por exemplo o livro de histórias ou o manual escolar. Estes eram os suportes de leitura e escrita que as crianças utilizavam com mais frequência no jardim-de-infância e em casa e, de alguma forma, exploravam individualmente ou a pares.

Sabendo que as revistas e os jornais entram com alguma frequência nas nossas casas, pudemos constatar que estes foram, seguramente, os que as crianças melhor identificaram, tendo em conta que serão mais utilizados pelos adultos; podemos assim concluir que lhes foi possibilitado, de algum modo, um contacto e até alguma exploração no meio familiar. Porém, como já referimos, na escola também existiam, usavam-se e manuseavam-se estes suportes de leitura e escrita com muita frequência, o que facilitou a apropriação dos mesmos por parte das crianças. A utilização deste tipo de suporte de leitura e escrita iria mostrar se as crianças possuíam conhecimentos sobre diferentes tipos de material impresso corrente e o que pudemos verificar foi que as crianças já conseguiam fazer alguma distinção entre imagem e texto escrito. Para a maioria o que se lê, o que interpreta e identifica o material é o texto escrito. Pudemos deste modo concluir que existe uma conciliação entre o que representa o texto e a consideração das propriedades do mesmo que remetem para a sua funcionalidade.
Certamente, e através deste estudo, pudemos inferir que, ao iniciarem a aprendizagem formal da leitura e da escrita no $1^{\mathrm{O}}$ ano de escolaridade, as crianças já reflectiram sobre a tarefa de ler e escrever. Elas construíram uma representação sobre os objectivos e a funcionalidade da leitura, os quais poderão surgir como bons preditores dos futuros resultados académicos. Sendo assim, esta pequena investigação, resultante da observação de um contexto de prática, revelou que a maioria das crianças da amostra apresentava possuir representações funcionais da leitura, sendo as de algumas mais elaboradas do que as de outras.

A par dos conhecimentos sobre a funcionalidade da leitura, todas as crianças evidenciaram possuir conhecimentos sobre diferentes suportes de leitura e escrita, à excepção dos que entraram um pouco em desuso ou que não estavam ao alcance das crianças.

Em suma, podemos concluir que o nível de elaboração das concepções das crianças que irão iniciar o $1^{\circ}$ ano de escolaridade, no que diz respeito à leitura e à escrita, é influenciado pelas práticas/contacto com a leitura e materiais impressos nos vários contextos onde estas interagem.

\section{REFERÊNCIAS}

AZEVEDO, Fernando. Educar para a literacia: para uma visão global e integradora da língua materna. In: AZEVEDO, Fernando (Org.). Língua Materna e Literatura Infantil: Elementos Nucleares para Professores do Ensino Básico. Lisboa: Lidel, 2006, p. 1-10.

BARDIN, Laurence. Análise de conteúdo. Lisboa: Edições 70, 2004.

FERREIRO, Emília. Com todas as letras. 14. ed. São Paulo: Cortez, 2007.

FERREIRO, Emília; TEBEROSKY, Ana. Psicogénese da Língua Escrita. 4. ed. Porto Alegre: Artmed Editora, 1999.

MATA, Lurdes. A descoberta da escrita: textos de apoio para educadores de infância. Lisboa: Direcção-Geral de Inovação e de Desenvolvimento Curricular, 2008.

ROSKOS, Kathleen; CHRISTIE, James; RICHGELS, Donald. The Essentials of Early Literacy Instruction. National Association for the Education of Young Children, 2003. Disponível em: <http://journal.naeyc.org/btj/200303/Essentials. pdf> Acesso em: 04 out. 2016.

SMITH, Miriam; DICKINSON, David. Early Language and Literacy Classroom Observation (ELLCO): Toolkit. Baltimore: Brookes Publishing, 2001.

TEALE, William; SULZBY, Elisabeth. Emergence Literacy: New perspectives. In: STRICKLAND, Dorothy; MORROW, Lesley (Orgs.). Emerging Literacy: Young children learn to read and write. 7. ed. Newmark, Delaware: International Reading Association, 1995.

WHITEHURST, Grover; LONIGAN, Christopher. Emergent literacy: development from pre-readers to readers. In: NEUMAN, Susan; DICKINSON, David (Orgs.). Handbook of early literacy research. London: Guiford Press, 2003, p. 11-29.

Recebido em: 10-10-2016.

Aprovado em: 22-05-2017. 